\title{
A Perception on How to Improve Students' Humane Attainment in Fine Arts Education
}

\author{
Bo Lin \\ University of Jinan \\ College of Fine Arts \\ Jinan, China \\ 961189194@qq.com
}

\begin{abstract}
China's fine arts education has a lot of shortcomings in terms of humane attainment, such as focusing too much on the imparting of drawing skills, techniques and knowledge while neglecting to cultivate the aesthetic feelings and instill the art culture in the heart of students. In the fine arts teaching practice, we can create an atmosphere of humanity in the classroom teaching and infiltrate humanism not only in the teaching of fine arts skills and techniques, but also in teaching evaluation. Strengthening the nurturing of traditional Chinese culture in fine arts education and improving the quality of western modern arts education in the teaching will be an effective way to improve students' humane attainments.
\end{abstract}

Keywords-fine arts education; humane attainment; Chinese traditional culture; western modernism

\section{INTRODUCTION}

Fine arts education could help develop humanity, cultivate humane attainments, and improve cultural taste. Fine arts education should expose students to distinctive emotions, attitudes, and values of different people, the richness of human society and meanwhile enables students to learn about the characteristics of fine arts, diversity of fine arts expression, and fine arts' unique contribution to the social life within the broad cultural context. Additionally, it would also bring up the students' enthusiasm for their country's fine arts tradition and the tolerance and respect for the world's diverse cultures.

Nowadays the limitation of China's fine arts education mainly lies in the inadequate infiltration of humanistic culture in the teaching and a lack of substantial change of the situations of "focusing on knowledge imparting and neglecting cultivation of attainment". We excessively emphasize the imparting and acceptance of drawing skills and techniques but ignore the cultivation of aesthetic feelings in students and the nurturing of fine arts cultures. Under these circumstances, the fine arts education has become a mere formality, resulting in some of the students having shallow cultural attainments and lacking profound base.

Humanistic spirit is a kind of mindset that places much importance on people and their view of values. It focuses on the meaning of man's existence, dignity, value, morality, traditional culture as well as the freedom and equality of people and harmony between people, society and the nature. The humanistic spirit is the core of people-oriented education.
It takes the perfection of personality as the ultimate goal of education, highlights the value of liberal arts, and winds the liberal education in the whole course of education, personalizing the entire education. It emphasizes the students' initiative thinking, feelings and discovery, the freedom, dignity and personality of people, and attaches high importance to learners' spontaneity, initiative and development potentials.

The study of humane attainment cultivating mode in fine arts education is to constantly cultivate the students' aesthetic consciousness on the basis of the cognition of beauty, highlight learners' creativity, personality and self-motivation, inspire the potential in the students, allowing them to create the works with uniqueness and polished artistic conception through the comparison of traditional fine arts and the modern fine arts. This will not only expose the students to the drawing techniques but also the diverse ways to express beauty in form and contents. Strengthening the cultivation of art talents with humane attainments should become the goal of fine arts education in China. With such a kind of fine arts education, we can evoke people's yearning for and pursuit of the true, the good and the beautiful as well as the spirit of freedom.

\section{INFILTRATION OF THE HUMANISTIC SPIRIT IN THE PRACTICAL TEACHING OF FINE ARTS}

The educational value of infiltrating humanistic spirit in the practical teaching of fine arts mainly lies in the following aspects. First, with the practical activities of fine arts, we can constantly enrich and sublimate students' fine arts experience and thus enable them to obtain the ability to sense, create and appreciate beauty and a healthy aesthetic taste. Second, in the practical teaching of fine arts, we can guide the students to continually discover and develop themselves, emphasize that each one should find the "individual reality" so as to achieve the collateral and harmonious development of fine arts learning and personality cultivation, and expose them to the meaning of existence, encouraging them to cherish and love life. Last but not least, by creating a relaxing, democratic teaching environment and learning atmosphere that encourages students' active participation, we will foster the humane attainments such as respect, caring, amity, cooperation, and sharing, enrich the students' emotions and spiritual pursuits, improve their personality and boost the harmonious development of body and mind. 
Teachers should strive to create an atmosphere of humanity in the classroom teaching of fine arts by preparing a relaxing teaching environment, fully respecting students' personalities and their different subjective senses, and encouraging them to be more imaginative and recognize their indispensability as an independent person in terms of thoughts, emotions, imagination and creativity. During the teaching, a new type of teacher-student relation shall be built to turn the students into the learning subject and the teachers play the role of facilitator. When dealing with teacher-student relationship, teachers must show their humane attainment, care for students, respect students' personality, get along with them sincerely, view them as equal individuals, respect their emotional experience, try to accept and understand the students, help them to build up confidence and bring their potentials into full play. They must be good at discovering and cultivating the personality and character of the students, so that they can create a free and domestic classroom teaching atmosphere and thus students will stay open-minded. Besides, it's necessary for teachers to respect each student's unique feeling and thinking about things, enabling their personality to be reflected and developed in their works. Only in this way could the students' works reveal their respective style and feature and put on a unique artistic charm.

The drawing techniques can be learned in many ways, but the most direct and overriding way is to learn them from a teacher. By teacher's demonstration, the students can obtain many sensory stimuli. For instance, the teacher's feeling, state, and action can be reflected in the brushwork, lines, tones, composition and understanding of a painting, which will directly attract the students' attention and inspire immediate feeling and keen interest in the students. In addition to the imparting of fine art techniques, the teachers must import corresponding cultural knowledge and theories, allowing the students to have an all-around understanding of such knowledge, which could further cultivate the students' artistic creativity.

The traditional subjective and one-way standards and forms used to evaluate the students could cause the conflicts and contrast between students and teachers, resulting in the students' loss of interest in learning the fine arts. In the evaluation process, teachers should pay attention to the emotional interaction with students and add humanity to the evaluative system. Therefore, in light of the law of students' mental development, the teachers must respect, understand and protect the students' artistic expression, and never excessively require and restrain them. Instead, in the arts-creating activity, teachers should give students active inspiration and confirmation in time, and encourage them to create artistic works with confidence and liveliness.

All in all, it is unwise for teachers to view the teaching of techniques as the only goal. Instead, they should orient the fine arts education toward humanistic spirit, and by means of imparting of knowledge and skills, allow the students to give free rein to their imagination and creativity in the humanistic fine arts teaching, and thus constantly improve the development of students' personality and humane attainment.

\section{REINFORCEMENT OF THE CHINESE TRADITIONAL CULTURE'S} INFLUENCE IN THE FINE ARTS EDUCATION

Chinese traditional culture is formed on the basis of the long-term fusion of the various mainstream cultures of the Chinese people, which is characterized by its stability. As an all-encompassing cultural ecology, it has incorporated different cultures into an organic unity. The Chinese traditional culture always centers on people, and prioritize the improving and surpassing of the ethnical spirit as well as the moral sentiments. Feng Youlan believes that the spirit of traditional Chinese culture embodies humanistic spirit, and defines the traits of traditional Chinese culture as the 'science of human', because the Chinese traditional culture places great importance on human beings. Indeed, both the simple humanitarian thoughts of the Confucian school and the emphasis on people's individual life in Taoism can reflect the path of traditional culture. Throughout the ages, the education emphasizes not only on the combination of culture and methods, but also on the cultivation of moral qualities in addition to the imparting of knowledge and techniques. As an important part of the Chinese traditional culture, the traditional arts used to serve as the spiritual support in the feudal society of China.

The fine arts education is mainly to temper the moral qualities, cultivate personality and realize the molding of people's spiritual world through the influence of arts. To achieve this goal, the spiritual treasure accumulated in the traditional culture will be the inexhaustible source. The shining sublime humanity in Chinese traditional culture, the ambition, love, integrity, self-improvement, aspiration, honesty and sacrifice and so on so forth, are the beliefs in the traditional culture, and shall be the beliefs that we hold to tamper humane attainment and improve personality.

The Chinese traditional painting is the freehand creation that emphasizes on expression and that applies the imagination to the integration of space and uses the limited ink to reflect boundless perception in painting. Therefore, the Chinese painting creation is a kind of reconstruction of life space. Since the Chinese painting takes the expression of spirit as the ultimate objective, Chinese painters pay special attention to the conscious representation of the beauty of nature, and they try to appreciate the divine life spirit by concentrated observation of nature. As a result, they are able to achieve the manifestation of life consciousness with rhythmical expression. Their paintings deliver the profound spirituality, take an exploration of expression discipline of "unity of man and nature" in Chinese traditional culture, and manifest the painting ideology and thoughtfulness by diverse means of association, perception and innovative drawing method, and through the studies of space, scenography and layers in Chinese and western painting. The painting is more about dealing with the relation between the form and spirit than the realistic reproduction, and meanwhile it generates the beauty of artistic perception. The viewer of the painting will not only learn about the superb drawing skills and technique of expression of the painter by viewing, appreciating and tasting the painting, but also improve their level of appreciation and humane attainment. 
Therefore, it is a realistic and urgent task to strengthen the influence of traditional culture and draw the essence from the historical legacy that has lasted thousands of years to improve the students' humane attainment and aesthetic attainment and found a solid cultural basis.

\section{INCORPORATION OF THE WESTERN MODERN ART EDUCATION IN TEACHING}

According to the essence of modern arts, human is the center and rationality is the channel. Its inclusiveness and expandability indicate the return of cultural spirit. The characteristics of modern arts, such as self-reflection, self-criticism, self-denial, and self-doubt, make it possible for the modern arts to become more critical, thoughtful and exploratory, which results in the changes in how viewers appreciate artworks. Observing this world from the perspective of humanities, we should indeed realize that it is high time that we changed our own way of thinking. We should also be aware that the modern arts provide us with the reference but by no means the only standard to evaluate the humanistic spirits.

By creating fresh art concepts and broadening art horizons, the modern arts reflect the confusion that is confronting modern people and react to the changes of the era. They raise the issue of art style to cultural level to interpret the reality. With an all-encompassing aesthetic view, the modern arts take in the local, foreign, elegant and vulgar arts synchronically and at the same time absorb the traditional and modern arts diachronically. They decompose the existing painting styles, shun the restriction from the established methods, materials and medium, and highlight people's personality. Everything can become art and art is everything, clearing up the constant boundary between life and arts. The creative attitude of modern arts frees the depressed personality and re-exploits people's potentials.

The modern artists apply unique methods of expression to their conveyance of their attitudes toward the society, life and nature. Among the modern works, a lot of them focus on the expression of subjective senses. Thorough analysis and explanation of these works will help the students to get a clearer understanding of the essence of modern arts. We don't have to completely agree with the value orientation of all the contemporary and modern art schools, but the creativity and imagination of modernistic arts and the innovative spirit in the modern art works are definitely the things our students lack. We have to admit that with the present progress of arts, the boundary between different fine arts have been broken, and they have developed a deeper fusion with other disciplines. In other words, the cultural and spiritual property of arts becomes more prominent. By analyzing the modern fine art works, we can guide the students to use their own imagination, apply and exercise divergent thinking to understanding the core concept of modernist arts from multiple perspectives. By comparing and bridging the modern art forms and other art forms, we can explain to the students that the traditional arts and modern arts, the Chinese arts and modern arts are complementary. To be an artist, they must have solid professional basis and cultural basis and a systematic understanding of knowledge on the oriental and western, traditional and modern arts.
We must seek and strive to construct the humanistic spirit that is in line with the development requirements of the era, combine the western countries' humanistic spirit with the Chinese traditional culture and the real life in order to enjoy the fruit of Chinese humanistic spirit.

\section{CONCLUSION}

Fine arts, as a way to reflect people's comprehension and evaluation of real life, have significant cognitive and educational meanings. Being the comprehensive reflection of the true, the good and the beautiful, and infest, the excellent fine art works will inspire and educate people with specific sensuous artistic images.

The function of fine arts education is not to forcefully instill knowledge but to inspire and encourage the painting viewers unknowingly by moving them with emotions that are implied the art works. As the art works are infiltrated with artists' aesthetic ideals and evaluation, the artists' attitude towards the true, the good and the beautiful in life contained in these works will make the viewers cross-reference their life with the artists unknowingly and call them up to judge what is right and what is wrong, what is beautiful and what is ugly. By strengthening the fostering of humane attainment in fine arts education, we can help the students to establish the correct aesthetic thoughts and feelings and healthy aesthetic concepts, improve the psychic structure, evoke their reflections on the world, enrich their feelings, and boost the healthy and harmonious development both physically and mentally. 